\title{
Improving Dictionary Skills in Ndebele
}

\author{
Samukele Hadebe, Department of African Languages and Literature, \\ University of Zimbabwe, Harare, Zimbabwe (samukeleh@yahoo.co.uk)
}

\begin{abstract}
This article proposes ways of improving dictionary skills amongst the Ndebele. One way of accomplishing this is incorporating the teaching of dictionary skills into teacher training syllabi. Teachers can impart their knowledge to students and a dictionary culture can develop for enhancing effective use of current dictionaries and helping in the compilation of future ones. In general lexicographers are aiming at producing dictionaries that are 'user-friendly', that is, accessible to their users. Current and future Ndebele dictionaries are likely to remain underutilised unless users develop requisite skills for dictionary use. This article outlines some aspects of dictionary studies that could be incorporated in the training syllabi for potential Ndebele language teachers. Anticipated problems of implementation and possible solutions to these problems are also discussed.
\end{abstract}

Keywords: DICTIONARY, DICTIONARY CULTURE, DICTIONARY SKILLS, REFERENCE NEEDS, REFERENCE SKILLS, USERS, USER-FRIENDLY, NDEBELE, LEXICOGRAPHY, CHANGE OF ATTITUDE

Opsomming: Verbetering van woordeboekvaardighede in Ndebele. Hierdie artikel stel maniere voor vir die verbetering van woordeboekvaardighede onder die Ndebeles. Een manier om dit te bewerkstellig is om die onderrig van woordeboekvaardighede in die opleidingsillabusse vir onderwysrs in te sluit. Onderwysers kan hul kennis aan studente oordra, en 'n woordeboekkultuur kan ontwikkel om die doeltreffende gebruik van huidige woordeboeke te verbeter en by die samestelling van toekomstiges te help. In die algemeen streef leksikograwe daarna om woordeboeke te lewer wat "gebruikersvriendelik", d.w.s., toeganklik vir hul gebruikers is. Huidige en toekomstige Ndebelewoordeboeke sal waarskynlik onderbenut bly mits gebruikers die nodige vaardighede vir woordeboekgebruik ontwikkel. Hierdie artikel skets 'n aantal aspekte van woordeboekstudie wat in die opleidingsillabusse vir toekomstige Ndebeletaalonderwysers ingesluit kan word. Verwagte probleme by die instelling en moontlike oplossings vir hierdie probleme word ook bespreek.

Sleutelwoorde: WOORDEBOEK, WOORDEBOEKKULTUUR, WOORDEBOEKVAARDIGHEDE, NASLAANBEHOEFTES, NASLAANVAARDIGHEDE, GEBRUIKERS, GEBRUIKERSVRIENDELIK, NDEBELE, LEKSIKOGRAFIE, VERANDERING VAN HOUDING

\section{Introduction}

This article deals with the teaching of dictionary-using skills with the long-term aim of developing a dictionary culture amongst the Ndebele $^{1}$ of Zimbabwe. By dictionary culture is meant, according to Hartmann and James (1998: 41): 'The 
critical awareness of the value and limitations of dictionaries and other reference works in a particular community.' The focus is on user perspective which investigates the reference skills and reference needs of dictionary users (Hartmann 2000: 11, 2001: 81, Béjoint 2000: 140, Svensén 1993: 13). User perspective in lexicography is a user-driven approach to dictionary-making and dictionary research. Reference skills are 'the abilities required on the part of the dictionary user to find the information being sought' (Hartmann and James 1998: 117), while reference needs are 'the circumstances that drive individuals to seek information in reference works such as dictionaries' (Hartmann and James 1998: 116).

Research on lexicography in the Ndebele language is still in its early stages. Actually, no research on Ndebele lexicography had been done until the establishment of the African Languages Lexical Project (ALLEX²), now the African Languages Research Institute (ALRI), at the University of Zimbabwe. Researchers in Ndebele lexicography are taking into cognisance the needs of dictionary users and the user perspective in dictionary studies.

Lexicographers in general are attempting to produce dictionaries that are 'user-friendly', that is, accessible to their users. Similarly, publishers of dictionaries also want products that are attractive and appealing to their markets. Thus the designation 'user-friendly' has become a catchword for lexicographers, publishers and critics alike. Béjoint (2000: 140) states:

Lexicographers in many countries have recently felt the need to go beyond empirical observations on the use of the general-purpose dictionary, seeking to find out what the users really do, as opposed to what they are believed to do, in order to make sure that the dictionary really corresponds to the needs of the public.

Similarly, lexicographers compiling Ndebele-language dictionaries, especially at ALRI, are concerned with fulfilling the users' expectations and needs. What has now been described as user needs in Ndebele, are in fact assumptions by dictionary editors. User-friendliness is difficult to attain, let alone to measure in a community where reference skills are relatively low and dictionary culture is non-existent.

As long as Ndebele dictionary users lack the requisite skills, current and possible future dictionaries in the language are likely to be underutilised until users have developed appropriate reference skills. There is a need to develop dictionary skills among the Ndebele to higher levels than those existing at present. Only after the community has a certain level of competence in dictionary use, can there be talk of user-friendliness and user needs. It is important, therefore, to establish user needs and user perspectives in Ndebele if the production of dictionaries were going to be of use. Such skills cannot be developed fully through informal learning and individual experience. They have to be taught formally. Dictionary makers have to know, and not only assume what they think users know. 
Writing on the significance of teaching dictionary skills in pedagogical lexicography, Dolezal and McCreary (1999: IX) state: 'As we look to the future development of this area, the mutual concerns of the teacher, the lexicographer and the learner/dictionary user could be the focus of pedagogical lexicography.'

The production of dictionaries is expensive, time-consuming and labourintensive. When these factors are taken into consideration, it would be uneconomic to continue producing reference works if such works will never be fully utilised beyond their function as cultural artefacts. Therefore, there is a need for user education in Ndebele, especially for teacher training. User education is defined by Hartmann and James (1998: 152) as 'the training of users in the reference skills in response to reference needs'. By training teachers to be good users themselves, it is envisaged that they could pass these skills on to students and eventually to society in general.

\section{The importance of teaching dictionary skills}

In Zimbabwe, books in indigenous languages are produced for the school market, and dictionaries are no exception. The development of a dictionary culture would be enhanced in the Ndebele community, especially in pupils through targeting teachers first. However, students cannot acquire dictionary skills by themselves without assistance from teachers. The initial focus should then be on teacher training. Hartmann (2001: 26) says: 'Teachers have rarely been offered the training needed to judge the benefits and limitations of particular dictionaries, or to instruct their students in the reference skills appropriate to guarantee successful consultation. Hardly ever are they in touch with lexicographers or dictionary researchers.' The problem of the lack in the teaching of reference skills is not peculiar to Ndebele, but is common in most languages. Landau (2001: 26) notes: 'The habit of using a dictionary is formed early in life, and if the skills to use it are neglected, the student may never be comfortable using dictionaries.' This observation is true for Ndebele dictionary users as well.

Writing on the possible solutions to this problem in general, Dolezal and McCreary (1999: XVIII) identified the following:

(a) make a more so-called 'user-friendly' dictionary (which in positive connotations must mean to develop a more readable format, better examples, better organization, etc., and in negative connotations must mean to dumb-it-down); and

(b) teach students reference skills.

As already mentioned above, the effectiveness of a user-friendly dictionary is partly dependent on the reference skills of the user (Svensén 1993: 16). Therefore, point (a) in the above quotation becomes secondary to point (b), which 
advocates the teaching of reference skills to students. The need to teach students about dictionaries is also noted by McKean (2000: 82): 'School dictionary lexicographers have been trying to encourage the teaching of dictionary activities and dictionary use in the classroom.'

To improve the lexicographic situation in Zimbabwe in general and Ndebele in particular, the teaching of reference skills should first target the teachers themselves. Teachers should be taught reference skills as part of their training in order to enable them to make maximum use of dictionary and reference books and impart this knowledge to their students. Teachers are in a better position than other researchers or even lexicographers to assess the students' lexicographic needs. If teachers gain competence in dictionary skills and pass on the skills to students, a dictionary culture would grow in the community.

Teachers and pupils, being the main users of dictionaries in the Ndebele community, can in the long run give a better evaluation of existing dictionaries and present views on shortcomings and needs in Ndebele lexicography. McKean (2000: 87) contends: 'The biggest area of improvement does not seem to be in the dictionary, but teacher training.' It is through improving the teachers' competence that dictionary culture could be taught to students and in turn produce more informed dictionary users in general. McKean further states: 'Better teacher training would, in time, lead to better dictionary consumers - a boon, not only for makers of school dictionaries, but for makers of commercial adult dictionaries as well.' Therefore, the choice of focusing on teacher training is justified.

The majority of Ndebele teachers live and work in the countryside and the few in urban areas are mostly in the poor schools in high-density suburbs. The common condition of schools in these circumstances is the lack of textbooks and other essential teaching aids. There are schools with no library and thousands others far from acquiring their first computer. In Zimbabwe there is still a partiality for science subjects, which are considered more important than arts subjects. This partiality has implications for resource allocation. The little resources a school is allocated firstly goes to purchasing science books and materials considered as a priority by both parents and educationists. When it comes to the arts subjects, English is given top priority both in terms of staffing, time and resource allocation. Therefore, in this general scarcity of resources in schools, the situation of the teacher of Ndebele is even more critical.

Teacher training in Zimbabwean colleges can be considered good by Third World standards. Teacher training colleges are satisfactorily equipped and staffed to produce on the average well-trained teachers. This is, with reference to the conventional colleges for secondary school teachers, the focus of this discussion. If he/she is equipped with the necessary reference skills and knowledge of the school conditions in the country, the teacher can use the little resources at his/her disposal in the best possible way. These could be a few textbooks and a handful of copies of the Ndebele dictionary.

Murphy (2000: 80) poses the questions: 'How can dictionary skills be 
applied and encouraged in grades in which "dictionary skills" are not listed in the official curriculum? ... How can we lexicographers reach out to teachers, teachers-in-training, and teacher trainers?' The same questions can be asked about Ndebele and the education system in Zimbabwe. The language syllabi of the two main teacher training colleges in the Ndebele-speaking provinces of Zimbabwe do not include dictionary skills among the skills taught. The Ndebele syllabi of the Hillside Teachers' College and United College of Education for 2002 both do not mention the teaching of reference skills ${ }^{3}$. Similarly, the school curricula are silent upon dictionary skills, probably assuming that these are acquired along the way.

In this article, it will be shown that there is no need specifically for separate courses on dictionary skills. The teaching of dictionary skills can be incorporated into courses on research skills and the use of learning aids, which are already a core part of the teacher training syllabi for Ndebele language teachers. As part of the research skills taught to student teachers in general, several aspects of lexicography could be included to complement these.

\section{Teaching aspects of lexicography}

The following areas can be proposed: general lexicography, history of the lexicography of $\mathrm{Nguni}^{4}$ and the Ndebele language, dictionary typology, lemmatisation in Nguni and Ndebele and dictionary structure. Each of these areas will now be discussed, with an elaboration of what each could cover.

\subsection{Lexicography in general}

There is a need to initiate teachers into the use of reference books of various types: dictionaries, thesauri, encyclopaedias and others. As there are not many types of reference works in Ndebele or, for that matter, in any African language, studying some aspects of English lexicography as reference point is inevitable. Dictionaries in the Ndebele language are, in any case, largely relying on general trends and traditions acquired from English language lexicography. Some problems of dictionary use in English could be highlighted in order to prepare the ground for a discussion of problems likely to face the Ndebele language student.

As stated earlier, teaching dictionary skills is part of language teaching. Alphabetic ordering in dictionaries should be discussed as well as its purported advantages and disadvantages. It is an important element of most dictionaries. This would also furnish a background for the discussion on lemmatisation in Nguni touched upon below. Teachers should be taught that, apart from the alphabetic system, other methods of ordering, for instance thematic ordering, are also used. 


\subsection{History of the lexicography of Nguni and the Ndebele language}

The first dictionaries and wordlists in Ndebele and other Nguni languages, especially Zulu, were bilingual, mainly targeted at missionaries who wanted to learn African languages. In these, there was a partiality towards Christian religion: 'Pelling's A Practical Ndebele Dictionary, has most of the terms relating to Christian religion and hardly any on African religion' (Hadebe 2000: 226). A similar bias is observed in Shona in Zimbabwe (Mpofu 2001: 244) and in Fan in Gabon (Mavoungou 2001: 123). In course of time, the bilingual dictionaries were also meant to assist Ndebele people learning English.

Compared to bilingual dictionaries, monolingual dictionaries have different issues to address. As far as the Ndebele language is concerned, various aspects can be learnt from such dictionaries. The role of a general-purpose monolingual dictionary for the native speaker is significant. The compilation of monolingual dictionaries in African languages is itself an important indicator of the status of these particular languages in society. The compilation of the first monolingual Ndebele dictionary had a number of interesting implications for the Ndebele language as far as its standardisation was concerned. For instance, a number of orthographic problems were addressed in the process of making this dictionary. Some of these include the division of compound words and the spelling of loan-words.

A historical background of Nguni lexicography in general and of Ndebele in particular will be useful for teachers. It would enhance their understanding of different types of dictionaries and why a particular type dominates the Ndebele and the Nguni languages. It could further be useful in their understanding of dictionary typology and dictionary structure. It could also give a background to the understanding of particular problems in Ndebele and Nguni lexicography, for instance the lack of consistency in lemmatisation and alphabetic ordering (see 3.5 below).

\subsection{Dictionary typology}

Teachers have to know the differences between types of dictionaries. This is important not only to guide students in using them appropriately, but also to advise their schools in purchasing the right kind of dictionaries. Knowledge of dictionary types enables the user to know what to expect in a particular type of dictionary. Knowledge of dictionary typology may assist in the understanding of dictionary structure.

Unless this knowledge is conveyed to teachers to pass on to students, dictionary users will continue to think that all dictionaries are the same and that anything can be looked up in any dictionary. Dolezal and McCreary (1999: XIII) state:

Results of empirical studies suggest that dictionary users do not distinguish among types of dictionaries; moreover, no matter how lexicographers might 
classify a 'thesaurus', students do not necessarily consider a thesaurus as a text belonging to a separate category of reference book.

As is shown in this quotation, many users of dictionaries, even of established languages like English, still have problems with distinguishing types of dictionaries. Acquisition of knowledge about basic distinctions in dictionaries could greatly enhance the use of dictionaries both as teaching and learning resources and as general reference works. Beyond establishing that there are dictionaries of different types, students in Ndebele are unlikely to master these basic distinctions in dictionary types by themselves. They will have to be taught about these differences.

\subsection{Dictionary structure}

The ability to use any dictionary, no matter how casually, presupposes and requires some basic knowledge of the structure of dictionaries. One such basic aspect, for instance, is the alphabetic ordering. Gouws (2001: 110) stresses the user-perspective in lexicography:

Modern-day lexicography is dominated by the user-perspective and the access structure of any new dictionary has to be user-driven, i.e. it has to be planned in accordance with the user profile of the dictionary and the needs and reference skills of a well-defined target user.

A comparative study of Ndebele and other Nguni language dictionaries focusing on dictionary structure could be relevant here. Although there is a generally expected structure in every dictionary, each dictionary has its own peculiar structure. Through the study of dictionary structure, teachers can learn how to use the dictionary as a tool for teaching in the classroom. The following areas could be helpful to a Ndebele language teacher:

\subsubsection{Grammatical information}

For Ndebele, having no comprehensive grammar book, the dictionary, for instance the recently published Isichazamazwi SesiNdebele (2001), could be useful for studying grammar. Information on aspects of grammar is usually given in the front matter of the dictionary. In the Isichazamazwi SesiNdebele, for instance, apart from a brief grammatical outline of the language in the front matter, the word category is given for each entry. Entries are marked as verbs, nouns, adjectives, adverbs, ideophones, pronouns, copulatives and conjunctives. Noun classes ${ }^{5}$ are also indicated while for verbs it is stated that they are either transitive or intransitive. Different types of morphemes, like tense morphemes, aspect morphemes, suffixes and reflexive morphemes are marked and defined. This is very useful information for language teachers. 


\subsubsection{Spelling}

Any general-purpose standard dictionary is assumed to reflect standard spelling. Teachers have to insist on their students spelling correctly, and the use of dictionaries is important for checking spelling. Ndebele still has unsolved spelling problems that might call for adjustment and reform. It is crucial for language users to be familiar with spelling conventions in the language, especially the division of compound words and the spelling of loan-words.

\subsubsection{Pronunciation}

Along with spelling goes the importance of pronunciation in dictionaries. Speakers need to spell words correctly and also pronounce them correctly. Most dictionaries in African languages mark tone because varying the tone changes the meaning of a particular word.

\subsubsection{Meaning}

Studies in general have shown that meaning is the first information users seek in a dictionary. The same assumedly applies to Ndebele users. Teachers have to be familiarised with types of meanings and the various possible senses a word may have. To save space, most senses are usually excluded from a generalpurpose dictionary. The use of synonyms in dictionaries should be taught as well.

Meaning is usually found through the context in which the particular word is used. Dictionary users have to be familiar with the description of meanings and how to use dictionaries in finding the meanings of words and expressions as they occur in texts. Commenting on dictionary meanings in general, Moon (1987: 86) states: 'Dictionaries traditionally record vocabulary as if meaning is something independent, inherent and unique to an item, and serving to distinguish it from all others.' Teaching some basics about types of meanings would be adequate for dictionary users to enable them to make full use of dictionaries as guides in deriving meanings of words and expressions in their various contexts.

\subsubsection{Vocabulary}

Vocabulary acquisition is important in all language teaching. Teachers have to help their students acquire as wide a vocabulary as possible. Students with a good command of their language would, for instance, reflect it in their use of synonyms and antonyms. The dictionary is one of the more reliable sources for enhancing vocabulary growth in students. For teaching Ndebele to non mother tongue speakers the appropriate vocabulary is essential. A significant number of both teachers and students come from minority language communities and learn and speak Ndebele at school ${ }^{6}$. 
In addition to teaching aspects like meaning or vocabulary, teachers need to cultivate in their students the ability to use the dictionary for more than looking up meaning, spelling and pronunciation. Teachers have to learn and teach the importance of the front matter and the back matter. It is a commonly acknowledged fact that users do not read instructions given in the front and back matter of dictionaries. This habit should be changed if users are to find dictionaries fully informative. Different ways of accessing information in dictionaries should be taught to teachers so that such knowledge could be conveyed to students at an early age.

As noted above, the objective to produce more user-friendly dictionaries has led lexicographers to make various innovations which often go unnoticed except perhaps by reviewers. Dolezal and McCreary (1999: XVIII) write:

Lexicographers painstakingly introduce more discrete definitions, examples, and grammatical information: many critiques of their work call for yet more nuanced information ..., while the learner, according to some studies, doggedly resists being a user of any type of dictionary.

Therefore, the user perspective in lexicography cannot attain its objective unless the user is efficient in dictionary use. For instance, children's dictionaries usually have a large font, coloured pictorial illustrations and all techniques designed for easy access of information. All this could, however, be a wasted effort on the part of the lexicographer and the publisher unless children have basic reference skills.

\subsection{Lemmatisation and alphabetic ordering in Nguni and Ndebele}

It is important to prepare teachers for potential problems students in Ndebele might face in using Nguni language dictionaries. There is the lemmatisation problem, inconsistencies in the alphabetic ordering of nouns by stem, prefix proper or initial vowel. For the lemmatisation of verbs and adjectives, the alphabetic ordering is based on the first letter of their respective stems.

The particular emphasis on lemmatisation problems in Ndebele should complement the study of dictionary structure. Lemmatisation by noun stem obviously makes access to entries more complicated than lemmatisation based on the initial letter of the noun, which in Ndebele is always a vowel. Traditionally, nouns in Nguni have largely been lemmatised according to noun stems. This presupposes users to have a certain level of understanding of grammar and to know the morphology of every word to be able to identify the stems.

\subsection{A case study of a monolingual Ndebele dictionary}

Teachers, as appliers of dictionaries, should be able to evaluate the effectiveness of dictionaries in fulfilling the objectives they purport to achieve. This is 
the essential part teachers have to play in assessing the usefulness of a dictionary for students and the best way it could be improved. By understanding the dictionary structure, teachers could easily assess students' needs and students' inadequacies in dictionary skills. This knowledge would be valuable for lexicographers and other researchers in language teaching, textbook writing and teaching methods.

A monolingual Ndebele dictionary, for instance Isichazamazwi SesiNdebele, could be used for a case study in dictionary criticism. This would enable the students to learn what is contained in the dictionary and what else they think should have been included. The dictionary criticism should broadly cover the text structure, macrostructure, microstructure, mediostructure and access structure.

\section{Anticipated problems in implementation}

Notwithstanding the expected advantages of teaching reference skills, there are some foreseeable problems. Some of the anticipated problems are societal attitudes, lack of competence and lack of training of lecturers.

\subsection{Attitude problems}

Attitude problems have a long history. Some sections of the population, especially the middle class, have negative attitudes towards all African languages in general. These people send their children to schools where African languages are not taught or are taught as optional subjects. Their negative attitude towards their mother tongues is likely to be transferred to dictionaries in these languages as well. Although this is a relatively small minority, they are the most influential people in the community. They tend to be the better educated and the well employed. Due to the colonially designed education system, these people still believe, falsely of course, that English or other languages of wider communication are the only languages worth learning. They want their children to start primary school in English, which is their second language.

Such negative attitudes held by people in strategic positions in society like teachers, doctors, education officers, and the like have implications for the money spent on dictionaries. In Zimbabwean schools, there is a tendency to give Ndebele as a subject fewer hours than subjects like English, Mathematics or Science. Similarly, the money schools spend on books is unequal, with Ndebele usually getting the least. This may mean that less reference books and dictionaries in Ndebele are bought for schools. In fact, even the staffing of Ndebele as a subject is at a disadvantage. Teachers trained to teach Ndebele are expected to teach other subjects like Mathematics and English when there is a general shortage of staff in the country. Ndebele is then given to untrained 
teachers because of the false belief that any mother tongue speaker having passed the school leaving examinations is competent enough to teach it. There are cases of teachers trained and qualified as language teachers who have never taught the subject for the whole of their careers. Therefore, some people with a knowledge of Ndebele lexicography might never pass on that knowledge to students, as they might be teaching other subjects like Mathematics for instance.

These negative attitudes ultimately lead to less investment of resources in Ndebele-language dictionaries by both researchers and publishers. Parents would buy dictionaries for their children if they think the language is an important school subject. The negative attitudes towards the language might cause few parents to purchase dictionaries. This has double implications. Firstly, there would be few users with access to dictionaries and that affects negatively on enhancing dictionary skills. Secondly, if less dictionaries are bought, publishers would in future shun publishing dictionaries. This also has a negative impact on the growth of Ndebele lexicography and consequently dictionary culture.

\subsection{Problems of incompetence}

There is a general dislike of Ndebele grammar as a subject amongst many students. Students at both secondary and tertiary colleges prefer literature and poetry to grammar. The problem of incompetence is further compounded by some teachers who even avoid teaching grammar at all. A number of reasons could be advanced for this situation, which of course is not peculiar to Ndebele. Firstly, Ndebele lacks grammar textbooks. Zulu textbooks like Uhlelo lwesiZulu are used, and some students have problems with the Zulu terminology. Secondly, most teachers are not confident in handling grammar because they were not properly taught themselves.

\subsection{Lack of teacher trainers}

Lastly, the question could be posed: Who will teach the teachers? There is a big possibility that even lecturers in teachers' colleges and universities in Zimbabwe have not themselves acquired these reference skills adequately.

Change, even if it is for the good, is sometimes resisted because people are not keen to abandon what they are used to. As the syllabi in teachers' colleges are an internal college or departmental affair, there can be no way of enforcing or ensuring that the appropriate skills are taught at all. One lecturer might teach it one year, and the following year another might abandon it. It therefore wholly depends on people on the ground realising the present deficiency and taking responsibility for improving it. 


\section{Possible solutions to problems of implementation}

\subsection{Changing attitudes}

Changing of attitude should be focused on specific groups within the community, that is, politicians, teachers, parents and students. Each group has to be approached with a different strategy for changing its attitude and the priority groups need attention first. First the politicians who are responsible for language and educational policies of the country should be won over. Once the policies are favourable to indigenous languages in education generally, those charged with implementation should be convinced. The desired policy changes should be to give Ndebele a meaningful role in education, preferably as a language of instruction for some subjects. It must be made mandatory that only appropriately qualified teachers should teach the language. Also, it should be allotted adequate time in the school timetables just like English or Mathematics.

Teachers and other professional people need evidence based on research to convince them of the importance of mother tongue instruction and consequently the acquisition of dictionary skills in Ndebele. A pilot study could perhaps be made with two or three different secondary schools. In each, two classes on the same level could be used for experimentation. One class is taught in Ndebele and also instructed to acquire dictionary skills, while the other is left with the current teaching methods and content. Then, at the end of a term, a test should be given to assess whether those who received instruction in dictionary skills would perform better than the control group. If the results of the experiment show (which it presumably will) that those students who received instruction in Ndebele and dictionary skills tend to perform better, then teachers will be motivated to adopt this method too. The good results obtained from adopting the new strategy may engender positive attitudes in teachers towards Ndebele in education. Parents generally want the best for their children and the best is what enables them to pass in school. With teachers convinced and their attitudes changed, parents would easily follow, especially if the government policy is already favourable. Students would consequently acquire a positive attitude towards Ndebele from their teachers, parents and from society in general.

\subsection{Addressing problems of incompetence}

The level of competence in grammar has generally to be raised in teachers as well as in students if they are to find using dictionaries easy and profitable. As noted earlier, the problem is also found elsewhere, for instance amongst English-language students as noted by Dolezal and McCreary (1999: XVII):

The unfortunate lack of language analysis skills among the current student population can only hinder their ability to comprehend and read dictionaries as 
reference texts: students who do not know the basic terminology of traditional or descriptive grammars will be hard pressed to decipher even the newest and best formatted information that is founded upon the latest theories of reading comprehension, grammatical theory and lexicology.

As mentioned earlier, most dictionaries teachers and students have been using prior to the publication of the monolingual Ndebele dictionary have noun entries entered by the first letter of the noun stem. To access a word implies to know the morphological structure of that word. Furthermore, there is no consistency in the dictionaries on the structure of certain nouns, especially loanwords. The metalanguage used in the Ndebele and other Nguni dictionaries is a language peculiar to grammar studies. If students cannot identify word categories correctly, the dictionary would be of little use as a language-learning tool. Therefore, the general lack of competence in grammar has to be changed, especially of language teachers.

\subsection{Addressing the problem of teacher trainers}

In colleges and universities, lecturers in Ndebele are still only a small number, not exceeding thirty at most. These could take part in a workshop conducted by lexicographers from ALRI who have received training and have experience in practical dictionary-making. That could be the starting point. In fact, these college and university lecturers have been invited periodically to ALRI seminars. There is a good working relationship already between the colleges and ALRI. Publishers could jointly fund the seminar as they too have always participated in these ALRI annual seminars.

\section{Advantages for Ndebele lexicography}

If the above proposals could be incorporated in the training syllabus for language teachers, a number of possible outcomes can be expected. To start with, teachers would be more knowledgeable and confident in their use of reference works. This ability would enable them not only to use dictionaries effectively in their teaching but also to teach reference skills to students. Once students and teachers have acquired reference skills and developed positive attitudes towards dictionaries, a dictionary culture would be growing amongst the Ndebele. As noted earlier, the Ndebele community, like most African communities, is generally poor and schools have very limited resources. Those limited resources should be used to the maximum. At present, with poorly developed research skills even amongst teachers, students are not putting the available resources to full use.

For the foreseeable future, dictionaries in Ndebele will be mainly for students or would rather be mainly used by students. In Zimbabwe, the general 
trend in publishing in African languages is that the school is the targeted market. This does not mean that dictionaries in Ndebele are aimed at a limited section of society. Actually, the potential market for dictionaries could be considered from primary school pupils to university students. Teachers and lecturers of all these various levels of pupils and students are similarly potential regular users of dictionaries. Once pupils and students develop the habit of using dictionaries, parents would have to acquire dictionary skills too, as they would be required to assist their children with homework.

Creative writers, who target the school market, would likewise have to rely on dictionaries for standard vocabulary and spelling, and so would textbook writers and publishers in general. Should there be such developments, interest in research on dictionaries is bound to grow.

Teachers would be interested in better dictionaries for teaching purposes, and textbook writers would be compelled to produce better works too. Publishers generally want to keep their market satisfied with the best that can possibly be produced. All these factors would combine to enhance research on dictionary-making in Ndebele.

At the moment, lexicographers and publishers are guessing what Ndebele dictionary users want. Ndebele dictionaries compiled in the past and being compiled at present, have not been and are not based on prior research on user needs and reference skills. Such research to establish user needs would not yield much, considering the low standard of reference skills amongst speakers. Once teachers have a basic knowledge of dictionaries and how they can best be utilised, there would be users able to give reliable feedback about particular dictionaries and user needs. At the moment, there is no point in finding out the extent of the development of reference skills in Ndebele because these skills are not being taught at all. Once they begin to be taught, research to evaluate the appropriateness of what is taught would be relevant.

The publication of the first monolingual Ndebele dictionary in 2001 was greeted with great enthusiasm, especially in Bulawayo. For many Ndebelespeaking people, the publication of the dictionary marked the revival of their language and culture from what is perceived as cultural oppression. The dictionary is considered with national pride. However, dictionaries must go beyond being just artefacts and symbols of national pride; they must become tools to improve communication.

Teaching of the relevant dictionary skills should develop a dictionary culture amongst the Ndebele. The conditions for such a development are favourable, judging from the enthusiasm people showed for the dictionary in newspaper articles, letters to editors and phone-ins on the radio after its launch. The linguistic climate 7 is now conducive to decisive changes in the teaching and promotion of Ndebele in Zimbabwe. Among potential users the motivation is already there; what now remains is to give them the requisite skills to make full use of dictionaries. 


\section{Conclusion}

It is possible to improve the reference skills of Ndebele dictionary users through teaching the appropriate dictionary skills. By focusing firstly on teacher-training, this knowledge would easily reach the school pupils and eventually the general Ndebele community. In this way, a dictionary culture could be enhanced which in turn would be instrumental in directing future lexicographic work based on the actual reference needs of dictionary users. Once teachers have acquired the appropriate skills and the teaching of reference skills is incorporated in the school syllabus, other additional means of enhancing dictionary skills could be employed as well. Some of these could be seminars and workshops on dictionaries for teachers, writers and other dictionary users. Even policy decisions could be made from an informed position, as most stakeholders would be more knowledgeable on dictionaries than they are currently. User-friendly dictionaries in Ndebele can be compiled when reference needs and reference skills of dictionary users are known.

\section{Acknowledgements}

This article forms part of the requirements of the Dr.Art. degree programme at the Faculty of Arts, University of Oslo, in which I had participated during the three years (1999-2002) I held a Ph.D. scholarship. The academic department to which I had been attached, the Department of Scandinavian Studies and Comparative Literature, is one of a very few which has a section for the study and practice of lexicography, with special emphasis on mother tongue lexicography. This article was written with advice from my supervisor Prof. Lars S. Vikør who is a leading authority on language standardisation and management in the Nordic countries and further. I am grateful for his comments. I also wish to extend my heartfelt thanks to Mrs Oddrun Grønvik, a Nordic lexicographer with a first-hand knowledge of African lexicography through her involvement with the ALLEX Project, whose valuable comments were incorporated in this final version.

\section{Endnotes}

1. This is the Ndebele language spoken in Zimbabwe as opposed to that spoken in the Republic of South Africa.

2. The ALLEX Project is a lexical project of cooperation involving the University of Zimbabwe, the University of Oslo and the University of Gothenburg, funded by NUFU (the Norwegian Universities' Committee for Development, Research and Education).

3. Hillside Teachers' College trains secondary school teachers, while the United College of Education is responsible for the training of primary school teachers.

4. Nguni refers to the sister languages Ndebele, Zulu, Xhosa and Swati. As these languages share a high percentage of their lexicon, speakers can refer to any of the language dictionaries, Ndebele for instance having used Zulu dictionaries. 
5. Ndebele nouns fall roughly within classes 1 to 18 , following the noun classification of Bantu languages by Carl Meinhof.

6. Ndebele is the officially sanctioned national language in the Matabeleland provinces of Zimbabwe where about five minority languages are also spoken. Speakers of these minorities learn Ndebele at school as if it were their first language and have difficulties with the vocabulary and pronunciation of Ndebele.

7. According to Vikør (1993: 179), linguistic climate refers to 'the ideological climate with regard to language use, language correctness and language planning'.

\section{Bibliography}

Béjoint, H. 2000. Modern Lexicography. New York: Oxford University Press.

Dolezal, F.T. and D.R. McCreary. 1999. Pedagogical Lexicography Today. Tübingen: Max Niemeyer.

Gouws, R.H. 2001. The Use of an Improved Access Structure in Dictionaries. Lexikos 11: 101-111.

Hadebe, S. 2000. Developing Terminology in African Languages with Special Reference to Ndebele. Chiwome, E.M. et al. (Eds.). 2000. Indigenous Knowledge and Technology in African and Diasporan Communities: 225-231. Harare: Mond Publishers.

Hadebe, S. et al. (Eds.). 2001. Isichazamazwi SesiNdebele. Harare: College Press.

Hartmann, R.R.K. 2000. European Lexicography: Perspectives on Dictionary Research, with Special Reference to the Countries of the European Union. Dictionaries 21: 1-21.

Hartmann, R.R.K. 2001. Teaching and Researching Lexicography. Essex: Pearson Education Ltd.

Hartmann, R.R.K. and G. James. 1998. Dictionary of Lexicography. London: Routledge.

Landau, S.I. 2001. Dictionaries: The Art and Craft of Lexicography. Second edition. Cambridge: Cambridge University Press.

Mavoungou, P.A. 2001. Macro- and Microstructural Issues in Mazuna Lexicography. Lexikos 11: 122-138.

McKean, E. 2000. Dictionary Activities in the Elementary Classroom: News for Lexicographers. Dictionaries 21: 81-89.

Moon, R. 1987. The Analysis of Meaning. Sinclair, J.M. (Ed.). 1987. Looking Up: An Account of the Cobuild Project in Lexical Computing: 86-103. London: Collins ELT.

Mpofu, N. 2001. Problems of Equivalence in Shona-English Bilingual Dictionaries. Lexikos 11: 242251.

Murphy, M.L. 2000. Dictionaries in the Classroom. Dictionaries 21: 78-80.

Nyembezi, S. 1991. Uhlelo lwesiZulu. Fifth revised edition. Pietermaritzburg: Shuter and Shooter.

Pelling, J. 1971. A Practical Ndebele Dictionary. Harare: Longman Zimbabwe.

Svensén, B. 1993. Practical Lexicography: Principles and Methods of Dictionary-Making. Oxford: Oxford University Press.

Vikør, L.S. 1993. The Nordic Languages. Oslo: Novus Press.

\section{Other References}

IsiNdebele Academic Study Syllabus. 2002. United College of Education.

IsiNdebele Syllabus. 2002. Hillside Teachers' College. 